\title{
Assessment of an Electric Vehicle Powertrain Model Based on Real-World Driving and Charging Cycles
}

\author{
Guanhao Du ${ }^{1}$, Student Member, IEEE, Wenping $\mathrm{Cao}^{1}$, Senior Member, IEEE, Shubo $\mathrm{Hu}^{2}$, Student \\ Member, IEEE, Zhengyu Lin ${ }^{1}$, Senior Member, IEEE, Jing Yang ${ }^{2}$, Member, IEEE, Tiejiang Yuan², \\ Member, IEEE
}

${ }^{1}$ School of Engineering and Applied Science, Aston University, Birmingham, U.K.

${ }^{2}$ School of Electrical Engineering, Dalian University of Technology, Dalian, P. R. China

\begin{abstract}
An analytical model for an electric vehicle (EV) powertrain has been developed in this paper to study the vehicular dynamics, based on a Nissan Leaf EV. The electrical components of the powertrain include a battery pack, a battery management system (BMS), a DC/DC converter, a DC/AC inverter, a permanent magnet synchronous motor (PMSM), and a control system while the mechanical system consists of power transmissions, axial shaft and vehicle wheels. The driving performance of the $\mathrm{EV}$ is studied through the realworld driving tests and simulation tests in Matlab/Simulink. In the analytical model, the vehicular dynamics is evaluated against changes in the vehicle velocity and acceleration, state of charge (SOC) of the battery, and the motor output power. Finally, a number of EVs are introduced in the system to optimize the power dispatch. The greenhouse gas emissions of EVs are analyzed under various driving and charging conditions, and compared with conventional internal combustion engine (ICE) vehicles. For a given driving cycle, Nissan Leaf can reduce $\mathrm{CO}_{2}$ emissions by $70 \%$, depending on its duty cycle and the way electricity is supplied.
\end{abstract}

Index Terms- Analytical model, electric vehicles, greenhouse gas emissions, powertrain, Nissan Leaf, V2G.

\section{INTRODUCTION}

$\mathrm{C}$ ONCERNS over global warming and depleting fossil fuels have led to the rapid development of electric vehicles (EVs) to replace internal combustion engine (ICE) vehicles. Presently, major industrial countries have published their energy policies and developed economic incentives to encourage the uptake of EVs [1]-[3]. The electrical components of the EV powertrain include a battery pack, a DC/DC converter, a DC/AC converter, an electrical machine and a control system [4][5]. The pure battery EVs utilise batteries as the power source to drive the vehicle [6]. They have zero atmospheric emissions and represent a means of eco-friendly personal transportation. On the contrary, ICE vehicles and hybrid EVs employ ICE engines as the whole or part of their power source, and thus generate $\mathrm{CO}_{2}$ emissions to some extent. The use of energy storage components can ensure a stable power supply and a quick response to the demand [7]-[9]. For example, fuel cell hybrid electric vehicles (FCHEVs) have a controllable input power from fuel cells and a supercapacitor to respond to the demand. But they are complex in control and costly in the marketplace. For instance, only 200 units of Toyota Mirai (FCHEV) are sold in Europe [10]. In the UK, there are 6008 charging stations for PEVs while there are only 11 hydrogen stations for FCHEVs. In terms of EV motor system, four types of electrical machines are commonly used in EVs. Compared with brushed DC motors, induction motors (IMs) and switched reluctance motors (SRMs), permanent magnet synchronous motors (PMSMs) have their advantages, such as better controllability, lighter weight, higher power density and efficiency. In this work, the EV is Nissan Leaf which utilizes a PMSM [11]-[13]. It is a pure EV and is one of the best-sellers in Europe. More than 300,000 cars are sold since its introduction in 2010, including 68,000 in the European market [14]. The Nissan Leaf powertrain includes electrical and mechanical systems. In the literature, EV powertrains are generally modeled by mechanical systems while electrical systems are overlooked [15]-[18]. In this paper, an extensive powertrain model has been built by analytical methods and Matlab/Simulink to include electrical systems.

\section{SIMULATION OF EV POWERTRAIN DYNAMIC SYSTEM}

A conventional EV powertrain is shown in Fig. 1. The electrical system consists of a PMSM, a battery management unit (BMU), one battery pack, a DC-DC converter and a DC$\mathrm{AC}$ inverter, and an electronic controller module. The mechanical system includes a transmission system, an axle shaft and wheels train system. The vehicle speed, motor torque and speed, and battery state of charge SOC are monitored in real time. The online route and vehicle dashboard are presented in Fig. 2. 


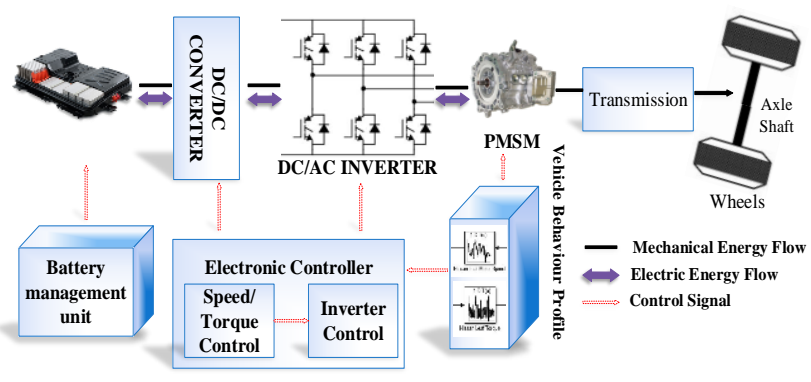

Fig. 1. The components of an EV powertrain.

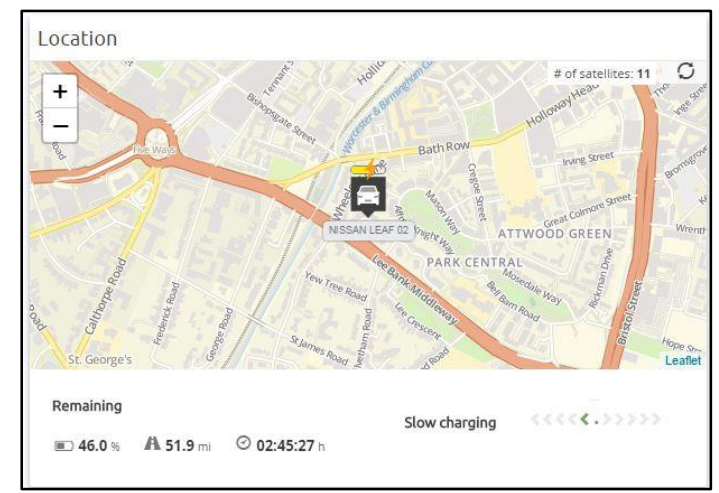

(a)

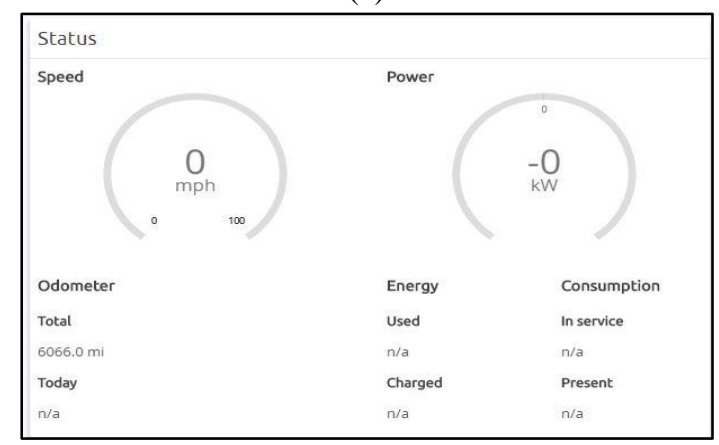

(b)

Fig. 2. Monitoring of the EV. (a) Online route. (b) Online dashboard of the Nissan Leaf EV.

\section{A. Battery Management System (BMS)}

The SOC of the battery is a key parameter as it indicates the amount of electrical energy stored in the battery. Typically, an adaptive extended Kalman filter (AEKF) is used for SOC estimation [19][20]. The Kalman filter (KF) is used to acquire the minimum mean squared error $\hat{\mathrm{z}}_{j}$ of the real state $\mathrm{z}_{j}$ based on measured input and output data. It is assumed that the system is linear and measurement noise is zero-mean, independent and Gaussian noise. If the system is nonlinear, the covariance matrix of the measurement in the KF will have measurement noise. By adopting the AEKF method in the BMS, it is convenient to update the parameters in real time. The nonlinear system model is described by:

$$
\begin{gathered}
z_{j+1}=f\left(z_{j}, U_{j}\right)+W_{j} \\
y_{j}=g\left(z_{j}, U_{j}\right)+v_{j}
\end{gathered}
$$

where $z_{j}$ is the system state vector at time index $j . U_{j}$ and $W_{j}$ are the measurable input and independent Gaussian noise, respectively. $f\left(z_{j}, U_{j}\right)$ is a nonlinear state transition function. $y_{j}$ is the measurable output and $g\left(z_{j}, U_{j}\right)$ is the nonlinear state transition function. $v_{j}$ is an independent Gaussian noise process with the statistical properties in the function.

By using an AEKF method for the BMS, the discrete function of SOC can be transferred.

$$
S_{j+1}=S_{j}-\frac{\gamma I_{k} \Delta t}{C_{n}}
$$

where $S_{j}$ and $S_{j+1}$ are the SOC at time $j, C_{n}$ is the nominal capacity, and $I_{k}$ is the current at time $j$. the current would be positive while discharging and negative while charging. $\gamma$ is the coulombic efficiency. Normally, $\gamma=1$ for discharging and $\gamma<1$ for charging in standard conditions.

Assuming that $z_{j}=S_{j}$ and considering the equivalent coulombic efficiency, the state function can be derived by,

$$
z_{k+1}=\left\{\begin{array}{c}
z_{k}-K_{q s}-\frac{I_{k} \Delta t \gamma_{c}}{C}+w_{k}, \quad I_{k}<0 \\
z_{k}-K_{q s}-\frac{I_{k} \Delta t \gamma_{c} \frac{\gamma_{c / 3}}{\gamma_{d}}}{C}+w_{k}, \quad I_{k}>0
\end{array}\right.
$$

where $\gamma_{c}$ and $\gamma_{d}$ are the equivalent charge and discharge coulombic efficiency, respectively. The base coulombic efficiency in Eq. 4 is $\gamma_{c / 3}$.

The combined function based on measurements is

$$
\begin{gathered}
y_{k}=g\left(I_{k}, z_{k}\right)+v_{k} \\
=K_{0}-R I_{k}-\frac{K_{1}}{z_{k}}-K_{2} z_{k}+K_{3} \ln \left(z_{k}\right)+K_{4} \ln \left(1-z_{k}\right)+v_{k}
\end{gathered}
$$

where $K_{0}, K_{1}, K_{2}, K_{3}$ and $K_{4}$ are the fitting coefficients, $R$ is the internal resistance and $v_{k}$ is the measurement noise.

According to Eqs. 4 and 5, a nonlinear discrete-time state space battery model is established. Therefore, the AEKF method would be adopted for estimating the SOC.

The SOC state is estimated by:

$$
\hat{\mathrm{z}}_{k / k-1}=\left\{\begin{array}{c}
\hat{\mathrm{z}}_{k-1 / k-1}-\frac{I_{k} \Delta t \gamma_{c}}{c}+q_{k}, \quad I_{k}<0 \\
\hat{\mathrm{z}}_{k-1 / k-1}-\frac{I_{k} \Delta t \gamma_{c} \frac{\gamma_{c / 3}}{\gamma_{d}}}{c}+q_{k}, \quad I_{k}>0
\end{array}\right.
$$

The error covariance is:

$$
P_{k / k-1}=P_{k-1 / k-1}+Q_{k}
$$

The Kalman gain capacitor and coefficient are:

$$
\begin{gathered}
\hat{C}_{k}=\left.\frac{\partial g\left(I_{k}, z_{k}\right)}{\partial z_{k}}\right|_{Z_{k}=\hat{\mathrm{z}}_{k} k}=\frac{K_{1}}{\left(\hat{\mathrm{z}}_{k / k-1}\right)^{2}}-K_{2}+\frac{K_{3}}{\hat{\mathrm{z}}_{k / k-1}}-\frac{K_{4}}{1-\hat{\mathrm{z}}_{k / k-1}} \\
K_{k}=P_{k / k-1} \hat{C}_{k}^{T}\left[\hat{C}_{k} P_{k / k-1} \hat{C}_{k}^{T}+R_{k}\right]^{-1}
\end{gathered}
$$

The measured SOC state is given by:

$$
\begin{gathered}
\tilde{z}_{k}=\ddot{z}_{k}-g\left(\hat{\mathrm{z}}_{k / k-1}, U_{k}\right)-r_{k} \\
\hat{\mathrm{z}}_{k / k}=\hat{\mathrm{z}}_{k / k-1}+K_{k} \tilde{z}_{k}=S_{c k}
\end{gathered}
$$

The error covariance measurement is:

$$
P_{k / k}=\left(I-K_{k} \tilde{C}_{k}\right) P_{k / k-1}
$$

\section{B. Configuration of the EV Battery Pack}

The structure of an EV battery pack is presented in Fig. 3. Two battery cells are connected in series and then in parallel with other two cells to forms a battery module. 48 battery 
modules are connected in series to form a battery pack. The electrical characteristics of battery cells are given in Table I. The cell voltage is rated at $3.75 \mathrm{~V}$ but can reach $4.2 \mathrm{~V}$. The battery pack is arranged into 3 sections. One section contains 24 modules in the center of the pack. Two other sections of 12 modules each are connected in series with the central section on the two sides. The battery pack voltage is rated at $360 \mathrm{~V}$ and its capacity is $24 \mathrm{kWh}$.

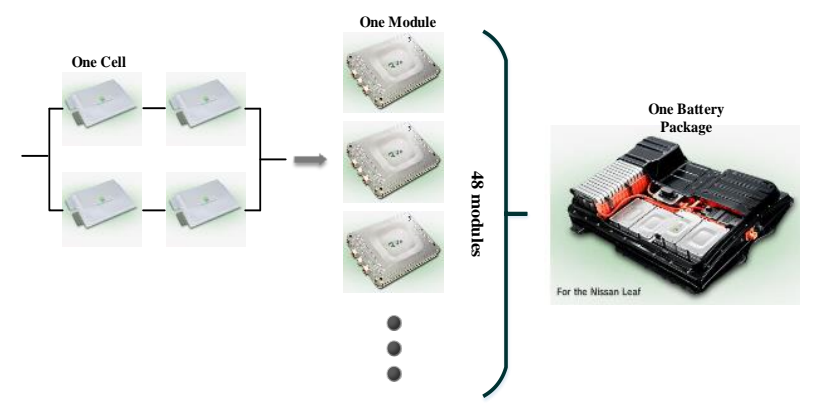

Fig. 3. The structure of an EV battery pack.

\begin{tabular}{|c|c|}
\hline Cell type & Laminate type \\
\hline Cathode active material & LiMn2O4 with $\mathrm{LiNiO} 2$ \\
\hline Capacity & $32.5 \mathrm{Ah}$ \\
\hline Nominal voltage & $3.75 \mathrm{~V}$ \\
\hline Exterior dimensions & $290 \times 216 \mathrm{~mm}(\mathrm{~L} \times \mathrm{W})$ \\
\hline Energy density & $317 \mathrm{Wh} / \mathrm{L}, 157 \mathrm{Wh} / \mathrm{kg}$ \\
\hline
\end{tabular}

\section{PMSM Model Development}

In the EV powertrain, a high-efficiency PMSM is used and is powered by the battery pack through a three-phase DC-AC inverter [21]. The state space equations of a PMSM in the synchronous $d-q$ reference frame are presented by

$$
\left\{\begin{array}{c}
\frac{d i_{d}}{d t}=\frac{1}{L_{s}}\left[U_{d}-R_{s} i_{d}-\omega_{r} L_{s} i_{q}\right] \\
\frac{d i_{q}}{d t}=\frac{1}{L_{s}}\left[U_{q}-R_{s} i_{q}-\omega_{r} L_{s} i_{d}-\omega_{r} \varphi_{r f}\right]
\end{array}\right.
$$

where $R_{s}$ and $L_{s}$ are the stator-phase resistance and inductance, respectively. $i_{d}$ and $i_{q}$ are the $d$ - and $q$-axis stator currents, and $\omega_{r}$ is the rotor electrical speed, respectively. $U_{d}$ and $U_{q}$ are the stator voltages in the $d-q$ reference frame, and $\varphi_{r f}$ is the rotor flux generated by the permanent magnets, respectively.

A discrete-time model is applied for calculating the $d-q$ reference currents in a sampling period in the vector control. By utilising a small sampling interval, the PMSM can be modeled in a discrete time, which is called Forward Euler discretization. The expression of the discrete-time equivalent equation is given by:

$$
\begin{gathered}
\left\{\begin{array}{c}
i_{d}(j+1)=i_{d}(j)+\frac{T_{s}}{L_{s}}\left[U_{d}(j)-R_{s} i_{d}(j)+E_{d}(j)\right] \\
i_{q}(j+1)=i_{q}(j)+\frac{T_{s}}{L_{s}}\left[U_{q}(j)-R_{s} i_{q}(j)+E_{q}(j)\right]
\end{array}\right. \\
\left\{\begin{array}{c}
E_{d}(j)=\omega_{r}(j) L_{s} i_{q}(j) \\
E_{q}(j)=\omega_{r}(j) L_{s} i_{d}(j)-\omega_{r}(j) \varphi_{f}
\end{array}\right.
\end{gathered}
$$

where $E_{d}(j)$ and $E_{q}(j)$ are the $d$ - and $q$-axis back electromotive force (EMF) at the $j$ th sampling instant; $i_{d}(j)$ and $i_{q}(j)$ are the $d$ - and $q$-axis state currents at the $j$ th sampling instant; $U_{d}(j)$ and $U_{q}(j)$ are the $d$ - and $q$-axis state voltages at the $j$ th sampling instant; $i_{d}(j+1)$ and $i_{q}(j+1)$ are the $d$-and $q$-axis state currents at the $(j+1)$ th sampling instant; $U_{d}(j)$ and $U_{q}(j)$ are the $d$-and $q$-axis state voltages at the $j$ th sampling instant, $T_{S}$ is the sampling period in the discrete-time model, respectively. The specifications of the PMSM are presented in Table II.

\section{TABLE II CHARACTERISTICS OF NISSAN LEAF} ELECTRICAL MOTOR

\begin{tabular}{ll}
\hline \multicolumn{1}{c}{ Parameter } & Value \\
\hline Rated power & $80 \mathrm{~kW}$ \\
Peak torque & $280 \mathrm{Nm}$ \\
Peak speed & $10,390 \mathrm{rpm}$ \\
Mass & $56 \mathrm{~kg}$ \\
Volume & $19 \mathrm{~L}$ \\
Stator O.D. & $19.8 \mathrm{~cm}$ \\
Rotor O.D. & $13.0 \mathrm{~cm}$ \\
Rotor pole & 8 \\
Stator slot & 48 \\
Motor efficiency & $96 \%$ \\
\hline
\end{tabular}

Vector control is widely used in the AC drives through a space vector pulse width modulation (SVPWM) technique. A typical configuration of vector control is shown in Fig. 4 [22]. The principle is to control the $d$-axis and $q$-axis currents of the motor as per the requirements of the powertrain. This is achieved through an inner control loop (current control) and an outer control loop (speed control), both utilising a PI regulator.

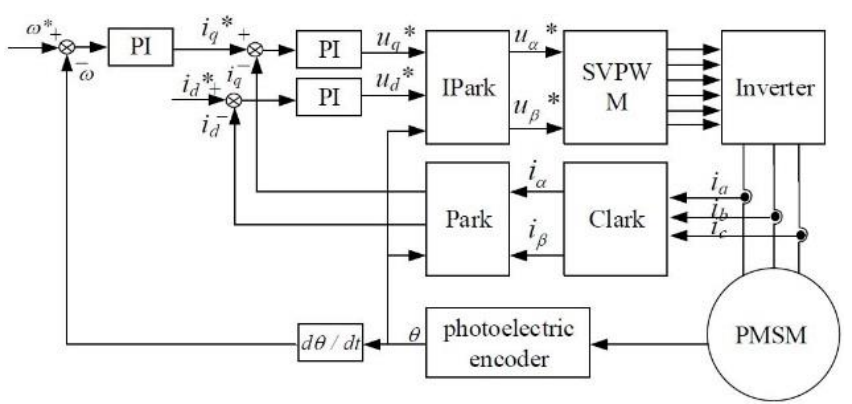

Fig. 4. Configuration of the vector control strategy.

\section{Vehicle dynamic model}

A vehicle dynamic model is shown in Fig. 5. According to the conventional mechanical system, the vehicle traction force $F_{T}$ with a friction force between the tyre and the road surface can be expressed as

$$
F_{T}=\frac{T_{w}}{r_{w}}-\frac{\delta_{w} \omega_{w}}{r_{w}}=\frac{\left(\sum G \gamma\right) T_{m}-\delta_{i t} \omega_{m}}{r_{w}}
$$




$$
\left\{\begin{array}{c}
\omega_{w}=\frac{T_{w}+r_{w}{ }^{2} m \omega_{w} \tau}{\delta_{w}+r_{w}{ }^{2} m(1-\tau)} \\
\tau=\frac{v_{w}-v_{T}}{\max \left(v_{w}, v_{T}\right)} \\
\delta_{i t}=\delta_{i t}{ }^{*}+\frac{\delta_{w}}{\sum G}
\end{array}\right.
$$

where $T_{w}, T_{m}, r_{w}$ and $\omega_{w}$ are the of the wheel torque, electromechanical torque, effective radius and angular acceleration of the wheels; $\delta_{w}$ and $\delta_{i t}$ are the wheels inertia and the total inertia; $G, \gamma, \tau$ and $m$ are the gear ratio, transmission efficiency, slip ratio and effective vehicle mass; $v_{T}$ and $v_{w}$ are the vehicle speed and wheel speed, respectively.

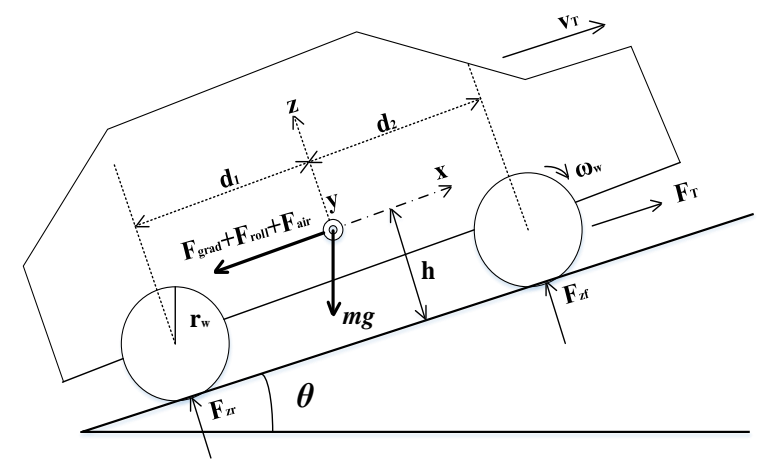

Fig. 5. The vehicle model based on the two drive wheels.

In Fig. 5, $d_{1}$ and $d_{2}$ are the horizontal distances from the front and the rear wheels to the center of gravity of the vehicle. $h$ is the vertical distance from the center of gravity to the road surface. The vertical force $\left(F_{z f}, F_{z r}\right)$ of the front and rear wheels in this two-wheel model can be expressed by:

$$
\left\{\begin{array}{c}
F_{z f}=\frac{d_{2} \mathrm{mg} \cos \theta-\mathrm{h}\left(\frac{\left(\sum G \gamma\right) T_{m}-\delta_{i t} \omega_{m}}{r_{W}}\right)}{d} \\
F_{z r}=\frac{d_{1} \mathrm{mg} \cos \theta+\mathrm{h}\left(\frac{\left(\sum G \gamma\right) T_{m}-\delta_{i t} \omega_{m}}{r_{w}}\right)}{d} \\
d=d_{1}+d_{2}
\end{array}\right.
$$

where $\theta, \omega_{m}$ and $d$ are the road angle, the motor acceleration, and the distance from the center to the front wheel $\left(d_{1}\right)$ to the rear wheel $\left(d_{2}\right)$, respectively.

From Fig. 5, the driving resistance is made up by the gradient resistance $F_{\text {grad }}$ on the road surface, the rolling resistance $F_{\text {roll }}$ generated by friction, and the aerodynamic resistance $F_{\text {air }}$ caused by air friction. Therefore, the resulting traction driving force $\dot{F}_{T}$ can be calculated by,

$$
\begin{gathered}
\dot{F}_{T}=F_{T}-\left(F_{\text {grad }}+F_{\text {roll }}+F_{\text {air }}\right) \\
=F_{T}-\left(m g \sin \theta+\epsilon_{T} m g+0.5 \partial_{d} \rho A_{T} v_{T}{ }^{2}\right)
\end{gathered}
$$

where $\epsilon_{T}, \partial_{d}, \rho$ and $A_{T}$ are the coefficients of the rolling resistance and aerodynamic drag, density of air, and the front area of the vehicle, respectively.

\section{E. Power optimisation model}

The total electrical power demand can be obtained by:

$$
P_{\text {total }}(i)=P_{E V}(i)+P_{L}(i)
$$

where $P_{E V}(i)$ is the total EV power at time $i$, and $P_{L}(i)$ is the load power at time $i$.

In order to minimize the difference between the actual power demand and the mean value of the power demand, an optimisation model is required.

$$
\begin{aligned}
& \min Z\left(P_{\text {total }}\right)=1 / N_{d} \sum_{h=1}^{N_{d}}\left(P_{\text {total }}(i)-\bar{P}_{\text {mean }}\right)^{2} \\
& =1 / N_{d} \sum_{h=1}^{N_{d}} P_{\text {total }}(i)^{2}-1 / N_{d} \sum_{h=1}^{N_{d}} \bar{P}_{\text {mean }}{ }^{2}
\end{aligned}
$$

where $\bar{P}_{\text {mean }}$ is the mean power demand.

Assuming $n_{a}$ and $n_{b}$ are the number of batteries in different EVs employed for charging (EV1) and discharging (EV2) purposes. The power demand for flexible charging and discharging can be expressed by:

$$
\left\{\begin{array}{c}
P_{E V 1}=\sum_{i=1}^{n_{a}} \sum_{j=1}^{N_{d}} P_{j} \times \varphi\left(P_{c j}, h\right) \times\left(1-\mathrm{G}_{\mathrm{ODT}}\right) \\
n_{a} \leq N_{B} ; P_{\text {load }} \leq \bar{P}_{\text {mean }} \\
P_{E V 2}=\sum_{i=1}^{n_{b}} \sum_{j=1}^{N_{d}} P_{j} \times \varphi\left(P_{d c j}, h\right) \times\left(1-\mathrm{G}_{\mathrm{ODT}}\right) \\
n_{b} \leq N_{B} ; P_{\text {load }} \geq \bar{P}_{\text {mean }} \\
P_{E V}=P_{E V 1}-P_{E V 2} ; n_{V}=n_{a}+n_{b}
\end{array}\right.
$$

where $\varphi\left(P_{c j}, h\right)$ and $\varphi\left(P_{d c j}, h\right)$ are the probability of a battery charging or discharging at time $h$, respectively. $\mathrm{G}_{\mathrm{ODT}}$ is the probability of vehicles on the road. $n_{V}$ is the total number of EVs.

By substituting Eqs. 22 and 23 into 21, the minimization problem can be developed as,

$$
\begin{gathered}
\min Z=\sum_{h=1}^{N_{d}}\left(P_{E V}(h)+P_{L}(h)\right)^{2} \\
=\sum_{h=1}^{N_{d}}\left(n_{a} \sum_{j=1}^{N_{d}} P_{j} \times \varphi\left(P_{c j}, h\right) \times(1-\mathrm{GODT})-\right. \\
\left.n_{b} \sum_{j=1}^{N_{d}} P_{j} \times \varphi\left(P_{d c j}, h\right) \times(1-\mathrm{GODT})+P_{L}(h)\right)^{2} \\
\text { Subject to }\left\{\begin{array}{l}
\sum f(h)+\sum q(h)=1 \\
f(h) \geq 0, q(h) \geq 0, \forall t \in\left[1, N_{d}\right]
\end{array}\right.
\end{gathered}
$$

where $Z$ is the object function with respect to the optimization problem. $f(h)$ and $q(h)$ are the probability of EVs charging/discharging actions at time $h$. Based on these calculations, EV performance can be evaluated using the real-world operating data.

\section{TEST RESULTS BASED ON REAL-WORLD DRIVING AND CHARGING CYCLES}

The developed powertrain model is verified by real-world operating data.

\section{A. Energy consumption under a daily driving cycle}

The test is based on one day operation (06/10/2017) of Nissan Leaf in Birmingham and its route is shown in Fig. 6. 


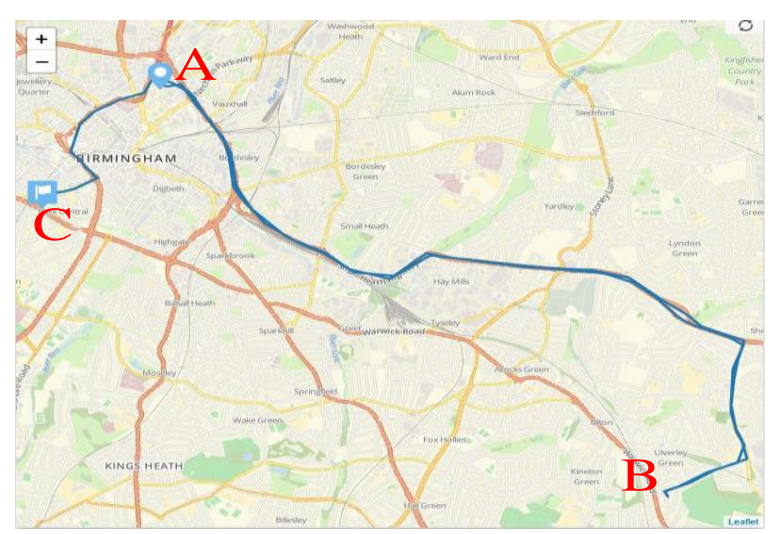

Fig. 6. The driving route of the EV.

The EV started from point A to B during the period 12:4813:00, and then went back to A from 13:25 to 13:40. Then it stopped at point $\mathrm{C}$ between 18:05 and 18:15. By removing the rest time, the total driving period on the day is presented in Fig. 7(a) with a condensed operating period of 32 minutes. The waveform of the motor torque and acceleration are illustrated in Fig. 7(b) and (c), receptively. During the driving period, the vehicle speed ranges from 0 to $53 \mathrm{mph}$ and the acceleration is generally less than $4 \mathrm{~m} / \mathrm{s}^{2}$, reflecting the road condition in urban Birmingham. The simulation results are presented in Figs. 8-11.

Fig. 8 shows the battery SOC results from simulation model and real tests. The red solid line represents the real test SOC and its tendency is shown in green dash line. The SOC results from the simulation model is presented in solid black. The two curves agree well with each other.

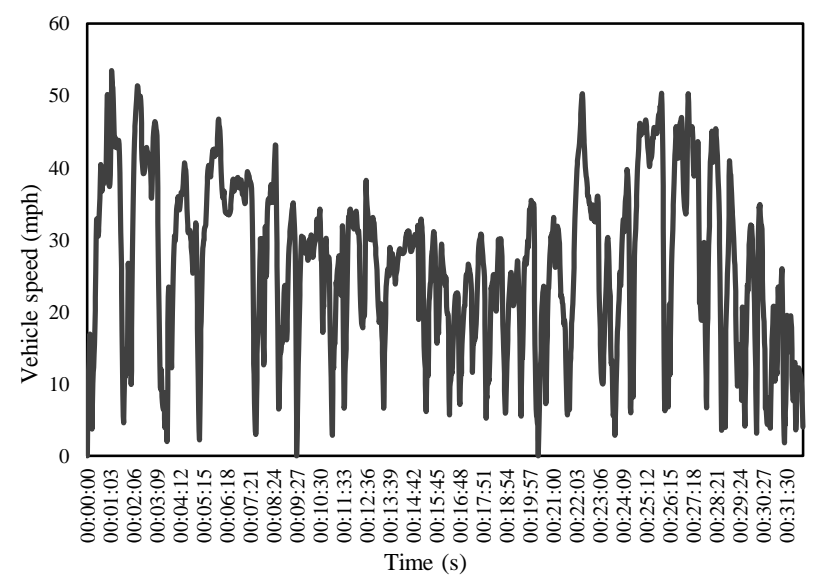

(a)

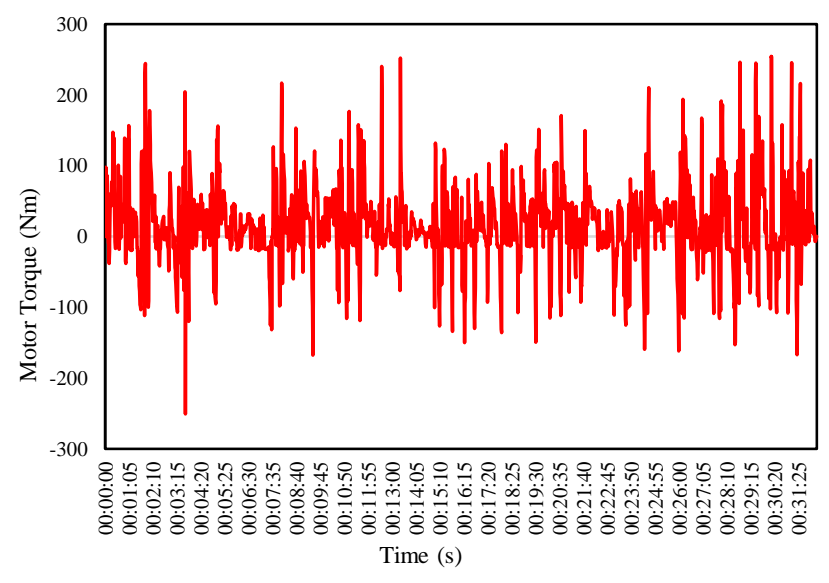

(b)

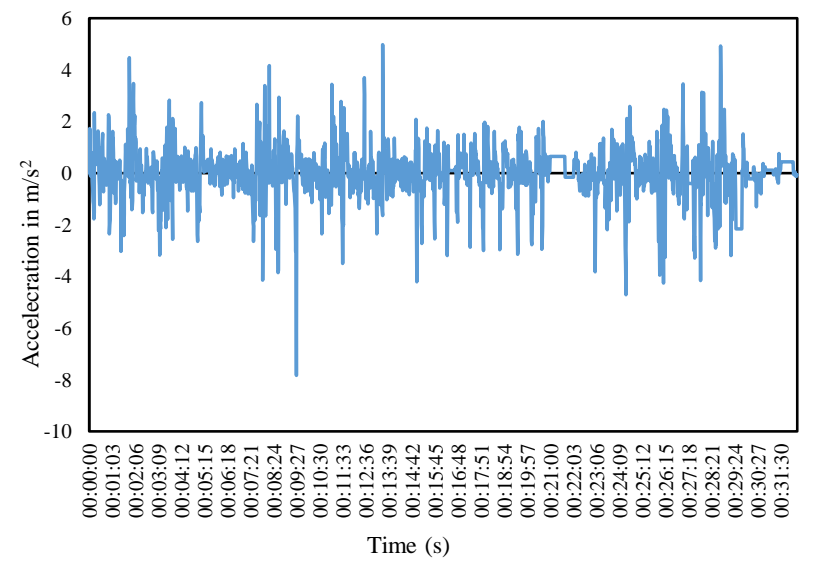

(c)

Fig. 7. EV performance. (a) Vehicle speed. (b) Motor torque. (c). The acceleration of the EV.

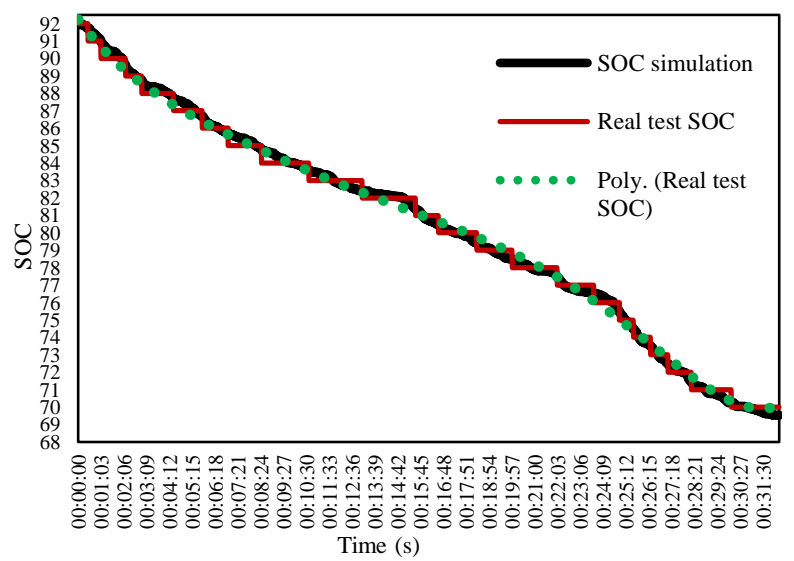

Fig. 8. Comparison of battery SOC between simulation and real tests. 


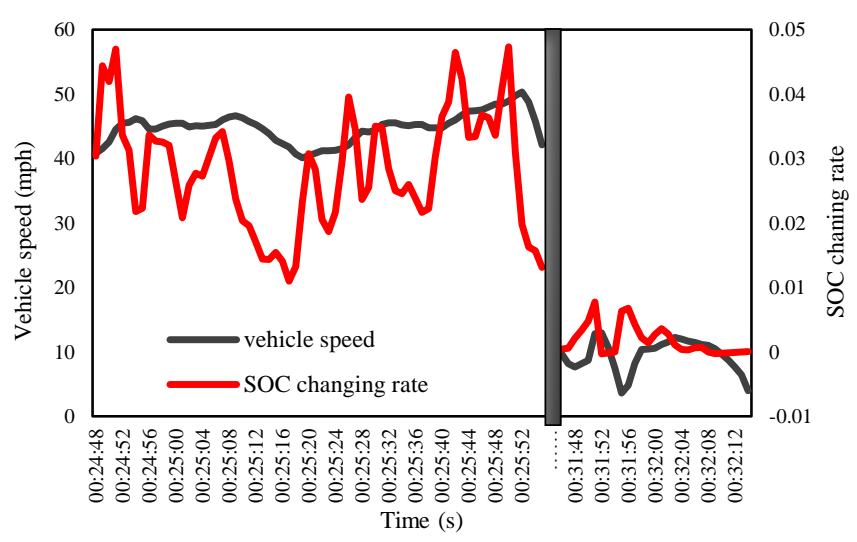

Fig. 9. Waveforms of vehicle speed and SOC changing rate.

Fig. 9 demonstrates a relationship between the vehicle speed and battery SOC. The dark solid line indicates the vehicle speed and the red line shows the changing rate of SOC. The average changing rate of SOC is around 0.03. By comparison, the SOC is under 0.008 during the period 00:31:47 to 00:32:14 in the low speed range. It is clear that the energy consumption increases with the vehicle speed. Fig. 10 further confirms the agreement between the battery SOC and energy consumption.

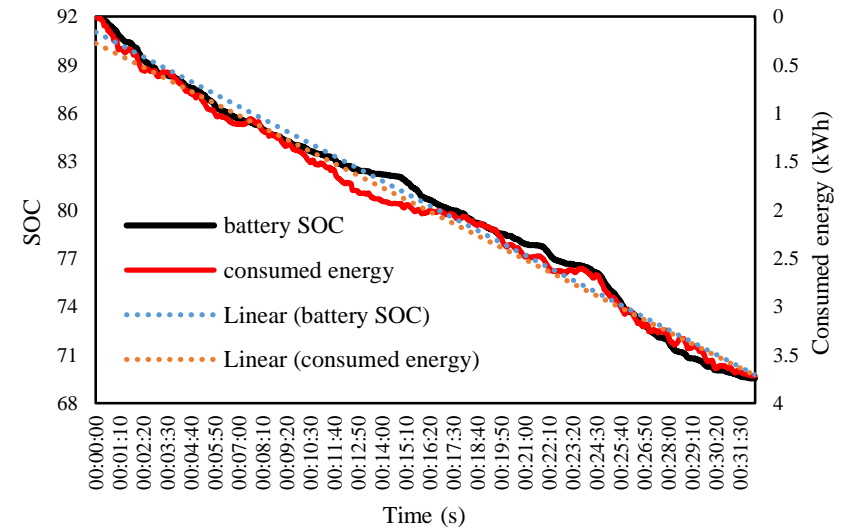

Fig. 10. The relationship between the battery SOC and energy consumption.

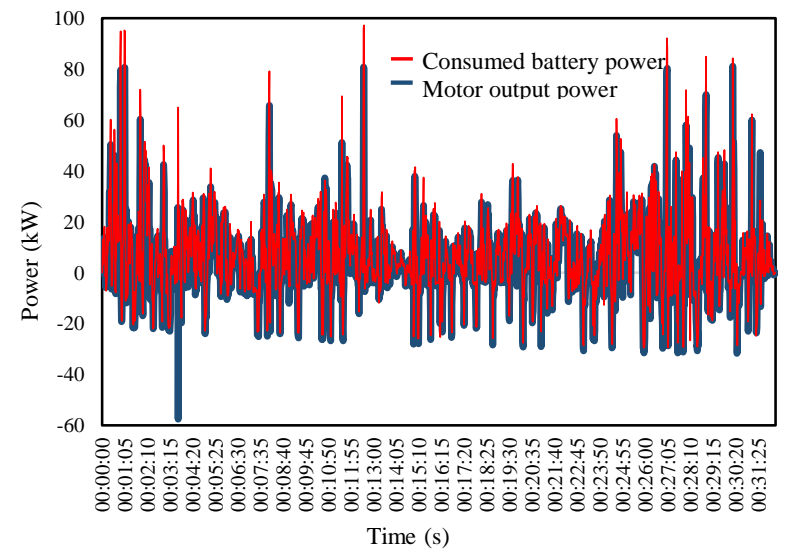

(a)

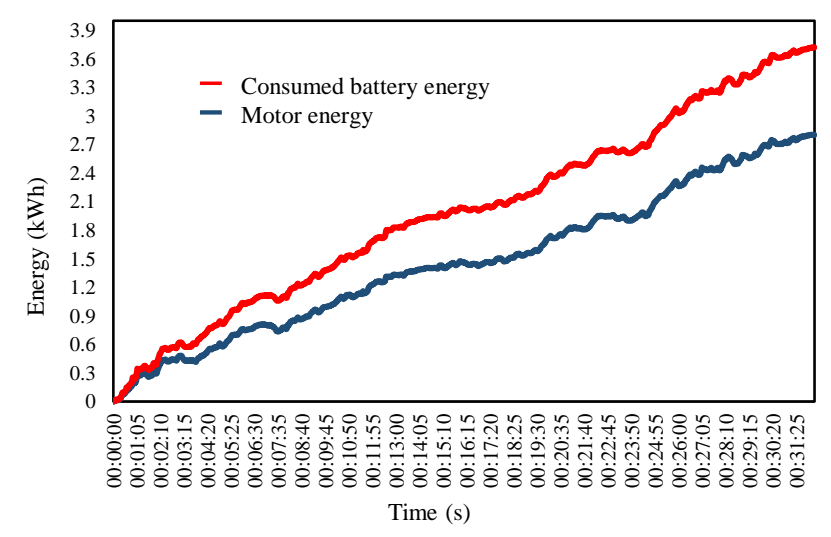

(b)

Fig. 11. Comparison of consumed power and energy. (a). Waveforms of motor power and battery power. (b). Waveforms of motor energy and battery energy.

Fig. 11(a) presents the motor power and consumed battery power during the driving cycle. Both waveforms present the similar fluctuations as the battery is the only power source. More specifically, Fig. 11(b) illustrates a comparison of energy delivered by the motor (red solid line) and the battery (blue solid line). The gap between the two is the energy lost in the transmission from the batteries to the motor.

The consumed motor energy and battery energy are given by,

$$
\begin{gathered}
E_{\text {mtotal }}=\sum P_{m}=2.802 \mathrm{kWh} \\
E_{\text {btotal }}=\sum P_{b}=3.718 \mathrm{kWh} \\
\eta=E_{\text {mtotal }} / E_{\text {btotal }}=75.4 \%
\end{gathered}
$$

where $E_{\text {mtotal }}$ is the consumed motor energy, $E_{\text {btotal }}$ is the consumed battery energy, $P_{m}$ is the motor output power, $P_{b}$ is the battery power and $\eta$ is the energy efficiency. The efficiency $(75.4 \%)$ is much better than that for conventional ICE vehicles (approximately 15\%), suggesting the benefits of adopting EVs in addition to reduced $\mathrm{CO}_{2}$ emissions.

This EV journal consumes $3.718 \mathrm{kWh}$ for a distance of 27.36 $\mathrm{km}$. The equivalent $\mathrm{CO}_{2}$ emissions are calculated [23][24] in order to compare between the EV and ICE vehicles, and between different electricity generation technologies. These are tabulated in Table III based on a compact ICE car Volswagen Golf 2012 [23]. It is clear that the use of EVs can significantly reduce the $\mathrm{CO}_{2}$ emissions for personal transportation but they are not emission-free. Depending on how electricity is generated, this EV journal would emit equivalent $\mathrm{CO}_{2}$ of $0.015-1.956 \mathrm{~kg}$. Hydro power is the lowest as it is renewable and low in cost.

Furthermore, an annual consumption is estimated on the same journal for 200 working days per year, as shown in Fig. 12. The amount of $\mathrm{CO}_{2}$ emissions produced by the $\mathrm{EV}$ are no more than $30 \%$ of an ICE vehicle. Combined with electricity generation from renewable energy, the environmental benefits of using EVs are significant. 
TABLE III COMPARIOSN OF CO 2 EMMISSIONS

\begin{tabular}{lll}
\hline $\begin{array}{c}\text { Type of } \\
\text { vehicles }\end{array}$ & \multicolumn{1}{c}{ Electricity source } & $\mathrm{CO}_{2}(\mathrm{~kg})$ \\
\hline ICE & \multicolumn{1}{c}{--} & 6.68 \\
$\mathrm{EV}$ & Conventional fuel & 1.96 \\
& Mixed (fuel and renewable) & 1.32 \\
& Solar & 0.26 \\
& Wind & 0.045 \\
& Hydro & 0.015 \\
\hline
\end{tabular}

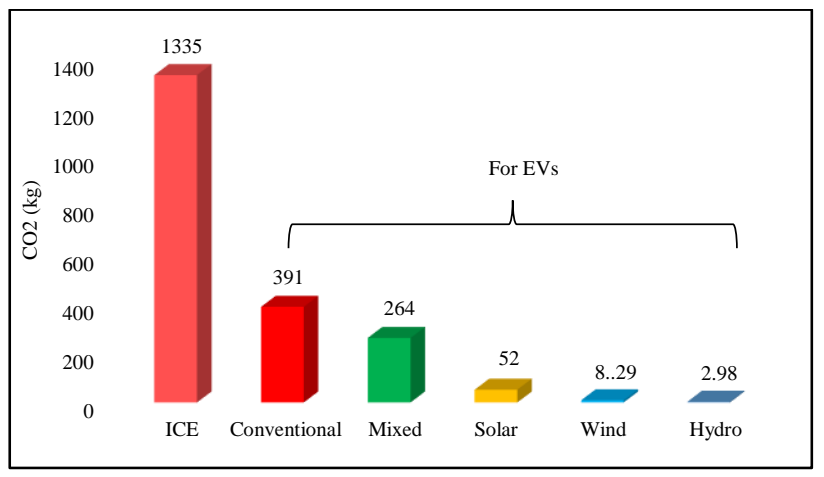

(b)

Fig. 12. Comparison of annual $\mathrm{CO}_{2}$ emissions.

\section{B. Power dispatch under a daily charging cycle}

In order to optimize the power dispatch, a number of similar EVs are involved based on the previous demand power, number of the vehicles, and probability of EVs connecting to the grid. The load profiles for different numbers of EVs are obtained and presented in Fig. 13.

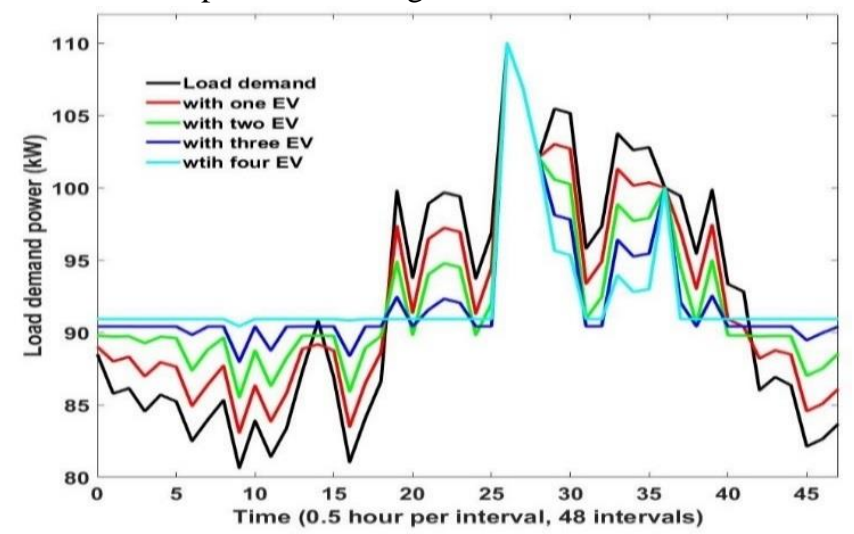

Fig. 13. Optimized and original power demand profiles.

Under this condition, the load demand in 24 hours is based on the European Bioenergy Research Institute (EBRI) building in Birmingham, which is equipped with several charging stations for Nissan Leaf. Among these is one vehicle-to-grid (V2G) charging station, which is used in this study. The demand is obtained in 48 intervals ( 0.5 hour each). The EV's V2G performance is evaluated according to the different number of EVs (1-4) connected to the grid. The probability of EV connecting to the power system network is derived from the rest time in the previous EV journal. In order to keep the EV operational for daily travels, the maximum energy for $\mathrm{V} 2 \mathrm{G}$ operation is limited. In this case, it is $70 \%$ of capacity which can be used for V2G grid support. From Fig. 13, the fluctuations of load demand are minimized by increasing the number of EVs for flexible charging and discharging operation. The optimized load demand would be much closer to the idealized mean load. However, as the EVs do not support the power network during driving periods, some fluctuations are not minimized in the figure.

\section{CONCLUSIONS}

In this paper, an analytical model of an EV powertrain has been presented, including both mechanical and electrical sub-systems. The system dynamic responses to changes in vehicle speed, acceleration, machine speed and torque have been studied in detail. An online AEKF SOC method is developed for battery management. The analytical model of the EV powertrain has been validated by simulation and actual test results from the test driving cycles. EV power and energy consumption based on the real driving tests can also be obtained to estimate their impact on the environments. Finally, a flexible power dispatch can be achieved by utilizing more EVs under controlled charging and discharging conditions. Therefore, EVs can be scheduled to support the power grid through V2G operation.

\section{REFERENCES}

[1] U. R. Prasanna and A. K. Rathore, "Dual three-pulsemodulation (DTPM) based high-frequency pulsating DC link two-stage three-phase inverter for electric/hybrid/fuel cell vehicles applications," IEEE J. Emerg. Sel. Topics Power Electron., vol. 2, no. 3, pp. 477-486, Sep. 2014.

[2] B. Zhou and T. Litter, "Local storage meets local demand: a technical solution to future power distribution system," IET Generation, Transmission \& Distribution, vol. 10, pp. 704-711, Feb. 2016.

[3] K. Rajashekara, "Present status and future trends in electric vehicle propulsion technologies," IEEE J. Emerg. Sel. Topics Power Electron.., vol. 1, no. 1, pp. 3-10, Mar. 2013.

[4] C. M. Lai, Y. H. Cheng, M. H. Hsieh and Y. C. Lin, "Development of a bidirectional DC/DC converter with dual-battery energy storage for hybrid electric vehicle system," IEEE Trans. Veh. Technol., vol. 67, no. 2, pp. 1036-1052, Feb. 2018.

[5] S. Akhegaonkar, L. Nouveliere, S. Glaser and F. Holzmann, "Smart and green ACC: energy and safety optimization strategies for EVs," IEEE Trans. on Systems, Man, and Cybernetics: Systems, vol. 48, no. 1, pp. 142153, Sep. 2016.

[6] H. A. Yavasoglu, J. Shen, C. Shi, M. Gokasan and A. Khaligh, "Power split control strategy for an EV 
powertrain with two propulsion machines," IEEE Trans. on Transportation Electrification, vol. 1, no. 4, pp. 382390, Dec. 2015.

[7] D. Zhou, A. A. Durra, I. Matraji, A. Ravey and F. Gao, "Online energy management strategy of fuel cell hybrid electric vehicles: a fractional-order extremum seeking method," IEEE Trans. Ind. Electro., vol. 65, pp. 67876799, Aug. 2018.

[8] H. S. Das, C. W. Tan and A. H. M. Yatim, "Fuel cell hybrid electric vehicles: A review on power conditioning units and topologies," Renewable and Sustainable Energy Reviews, vol. 76, pp. 268-291, Sep. 2017.

[9] H. Fathabadi, "Fuel cell hybrid electric vehicle (FCHEV): Novel fuel cell/SC hybrid power generation system," Energy Conversion and Management, vol. 156, pp. 192201, Jan. 2018.

[10] TOYOTA Global Newsroom. Toyota sells 1.52 million electrified vehicles in 2017, three years ahead of 2020 target [Online]. Available: https://newsroom.toyota.co.jp/en/corporate/20966057.ht ml?adid=ag478 mail\&padid=ag478 mail

[11] J. D. Widmer, R. Martin and M. Kimiabeigi, "Electric vehicle traction motors without rare earth magnets," Sustainable Materials and Technologies, vol. 3, pp. 7-13, Apr. 2015.

[12] J. Santiago, H. Bernhoff, B. Ekergard, S. Eriksson, S. Ferhatovic, R. Waters, and M. Leijon, "Electrical motor drivelines in commercial all-electric vehicles: a review," IEEE Trans. Veh. Technol, vol. 61, no. 2, pp. 475-484, Feb. 2012.

[13]H. Busch, M. Duoba, E. Rask and M. Meyer, "Advanced powertrain research facility AVTA Nissan leaf testing and analysis," Energy Efficiency and Renewable Energy, 2012.

[14] Nissan Official Newsroom. Nissan delivers 300,000th Nissan Leaf [Online]. Available: http://nissannews.com/en-US/nissan/usa/channels/usunited-states-nissan/releases/nissan-delivers-300-000thnissan-leaf

[15]X. Y. Zhou, D. T. Qin and J. J. Hu, "Multi-objective optimization design and performance evaluation for plugin hybrid electric vehicle powertrains," Applied Energy, vol. 208, pp. 1608-1625, Dec. 2017.

[16] E. A. Grunditz and T. Thiringer, "Characterizing BEV powertrain energy consumption, efficiency, and range during official and drive cycles from Gothenburg, Sweden," IEEE Trans. Veh. Technol., vol. 65, no. 6, pp. 3964-3980, Jun. 2016.

[17]F. L. Mapelli, D. Tarsitano and M. Mauri, "Plug-in hybrid vehicle: modeling, prototype realization, and inverter losses reduction analysis," IEEE Trans. Ind. Electro., vol. 57, pp. 598-607, 2010.

[18] A. Nair and K. R. Rajagopal, "Generic model of an electric vehicle for dynamic simulation and performance prediction," Electrical Machines and Systems 2010 International Conf., pp. 753-757, 2010.

[19] J. Wang, J. Guo and D. Lei, "An adaptive Kalman filtering based state of charge combined estimator for electric vehicle battery pack," Energy Conversion and Management, Vol. 50, pp. 3182-3186, 2009.

[20] J. F. Yang, B. Xia, Y. L. Shang, W. X. Huang and C. C. $\mathrm{Mi}$, "Adaptive state-of-charge estimation based on a split battery model for electric vehicle applications," IEEE Trans. Veh. Technol., vol. 66, no. 12, pp. 10889-10898, Dec. 2017.

[21]C. Shi, Y. C. Tang and A. Khaligh, "A single-phase integrated onboard battery charger using propulsion system for plug-in electric vehicles," IEEE Trans. Veh. Technol., Vol. 66, no. 12, pp. 10899-10910, Dec. 2017.

[22]F. L. Zhang, X. L. Wang, Q. X. Liao and C. Gu, "Highly integrated bidirectional vehicle to grid (V2G) for electric vehicles based on open winding permanent magnet synchronous motor," IEEE International Conference on Electrical Machines and Systems (ICEMS), Oct. 2017.

[23]E. Pike, "Calculating electric drive vehicle greenhouse gas emissions," International Council on Clean Transportation (ICCT), Aug. 2012.

[24] "New car $\mathrm{CO}_{2}$ report 2017, the $16^{\text {th }}$ edition," The Society of Motor Manufacturers and Traders Ltd., 2017.

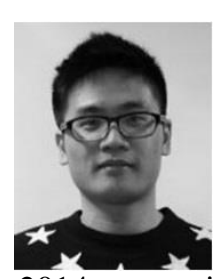

Guanhao Du (S'14) received the B.Eng degree in electrical engineering and automation from Soochow University, Suzhou, China, and the M.Sc degree in electrical power engineering from Newcastle University, Newcastle, UK, in 2013 and 2014, respectively. He is currently working toward the $\mathrm{PhD}$ degree in smart grids at Aston University, Birmingham, UK.

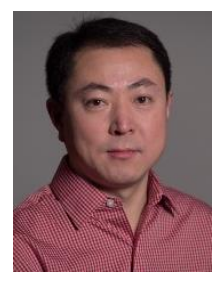

Wenping Cao (M'05-SM'11) received the B.Eng in electrical engineering from Beijing Jiaotong University, Beijing, China, in 1991, and the Ph.D. degree in electrical machines and drives from the University of Nottingham, Nottingham, U.K., in 2004. He is currently Chair Professor of Electrical Power Engineering and Head of Power Electronics, Machines and Power System (PEMPS) Group at Aston University, Birmingham, U.K.

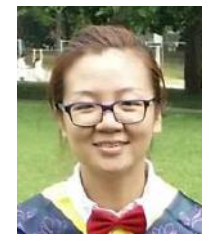

Shubo Hu (S'14) received the B.S. degree in electrical engineering from Dalian University of Technology, Dalian, China, in 2012. Currently, she is a doctoral candidate in school of electrical engineering, Dalian University of Technology, China. 


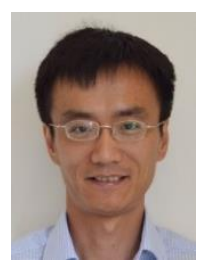

Zhengyu Lin (S'03-M'05-SM'10) received the B.Sc. and M.Sc. degrees from the College of Electrical Engineering, Zhejiang University, Hangzhou, China, in 1998 and 2001, respectively, and the Ph.D. degree from Heriot-Watt University, Edinburgh, U.K., in 2005. He is currently a Lecturer in Department of Electrical, Electronic and Power Engineering, Aston University, Birmingham, U.K.

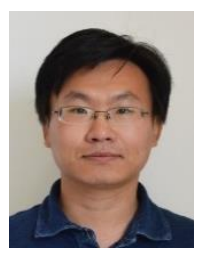

Jind Yang (S'08-M'11) received the B.E. and M.Sc. degrees from North China Electric Power University, Baoding, China, in 2003 and 2006, respectively, and the Ph.D. degree from the University of Glasgow, Glasgow, U.K., in 2011, all in electrical engineering.

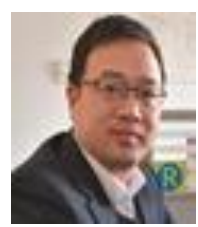

Prof Tiejiang Yuan (M'11) received his MSc and $\mathrm{PhD}$ degrees in power systems from Xinjiang University, China, in 2009 and 2012, respectively. $\mathrm{He}$ is a Professor with the School of Electrical Engineering, Dalian University of Technology, China. 